\title{
Making Aquaponics a Business: A Framework
}

\author{
Lorena Silva Araújo 1미, Karel J. Keesman ${ }^{1, *(1)}$ and Simon Goddek ${ }^{2}$ \\ 1 Mathematical and Statistical Methods (Biometris), Department of Plant Sciences, Wageningen University, \\ P.O. Box 16, 6700 AA Wageningen, The Netherlands; lorena.silvaaraujo@wur.nl \\ 2 SINTEF Nord AS, Postboks 118, 9252 Tromsø, Norway; simon.goddek@sintef.no \\ * Correspondence: karel.keesman@wur.nl
}

Citation: Silva Araújo, L.; Keesman, K.J.; Goddek, S. Making Aquaponics a Business: A Framework. Water 2021, 13, 2978. https://doi.org/10.3390/ w13212978

Academic Editor:

Adriana Bruggeman

Received: 16 September 2021

Accepted: 18 October 2021

Published: 22 October 2021

Publisher's Note: MDPI stays neutral with regard to jurisdictional claims in published maps and institutional affiliations.

Copyright: (c) 2021 by the authors. Licensee MDPI, Basel, Switzerland. This article is an open access article distributed under the terms and conditions of the Creative Commons Attribution (CC BY) license (https:// creativecommons.org/licenses/by/ $4.0 /)$.

\begin{abstract}
Commercial aquaponics systems remain a challenge independent of the country, fish, plant species, or system design type. Most aquaponics systems are made by hobbyists, with aquaponics not being the main source of income. As such, scholars and practitioners have long debated the real profitability of aquaponics systems. With the growth of the aquaponics industry and commercial businesses, sustainable economic viability is necessary. Recently, considerable literature has been published around the theme of aquaponics systems design but there is a gap in the literature regarding the business aspect of this. Moreover, only by acquiring the enterprise knowledge of planning a business case, obtaining funds, and running and maintaining a business will this industry be able to grow. This paper intends to create a directory of possible considerations to plan for a viable commercial aquaponics system by uniting already established business frameworks and adapting them to the aquaponics industry. This framework proposes a guide to evaluate the economic feasibility of the enterprise depending on the revenues, costs and investments needed for the chosen system within its operations, market, and environment.
\end{abstract}

Keywords: aquaponics; business case; framework; economic viability; guide; integrated agri-aquaculture systems

\section{Introduction}

Aquaponics is still a recent study field. One of the first papers that addressed it in the late 1970s did not even call it aquaponics, rather: "Combined production of fish and plants in recirculating water" [1]. According to the pool of research in the Web of Science database, until 2010 there were less than 50 papers that cited aquaponics and from 2011 to 2021 (year-to-date) there were over 1500 papers. There are still many challenges which are faced in aquaponics, such as technical issues, access to resources and investments, and marketing [2-7].

The current landscape for aquaponics has been investigated in recent surveys [8-10]. As can be seen from these surveys, aquaponics practitioners are very new in the total food production system landscape and commercial systems are still a minority within this community. Aside from this, there is a knowledge gap of technical and operational issues but also in how to make aquaponics profitable [2,11]. Some factors associated with profitability are: aquaponics as the primary source of income, gross sales revenue, greater aquaponics knowledge, and sales of non-food products [12]. Most of the scientific knowledge acquired to date addresses the production system from a technical and scientific approach rather than looking into the economic issues [13]. A 2019 review shows that, from all the publications on aquaponics from 1980 to $2017,58 \%$ had no economic references. Of these publications, the majority $(82 \%)$ focused on different elements of the production system, while few $(18 \%)$ dealt with the economics or management of commercial aquaponics [13].

The objective of this paper is to introduce and discuss a framework. This framework contains elements to be considered to evaluate the feasibility of an aquaponics commercial system and can guide practitioners to establish and leverage the viability and profitability 
of aquaponics systems throughout the world. Finally, the framework is intended to be simple yet robust enough to be useful to as many people as possible, not only researchers but also practitioners and even investors. Only by acquiring the technical and business knowledge of planning a business case, obtaining funds, and running and maintaining a company will this industry be able to grow and prove its expected sustainability.

\section{Materials and Methods}

Aquaponics is a hard business to apply to a one-size-fits-all approach since it depends on numerous possibilities of markets, environment, and investments. Therefore, the idea behind this paper is not to create a methodology or a model, but rather a framework. According to the Cambridge dictionary, a framework is "a supporting structure around which something can be built", while a methodology is "a set of methods used in a particular area of study or activity" and a model is "something such as an object, plan, or set of rules that is used to show what something else is like or how it works" [14]. While a model is a set of rules and a methodology is a set of methods, a framework is a supporting structure with a broader sense of guiding which still allows for adaptations to its own characteristics.

The first step taken to create this framework was to evaluate the gaps currently presented in the surveys and publications and to insert them into the context of what is needed for an aquaponics venture. Following this, a focused literature review was executed with some of the already established frameworks, aiming to make the framework as thorough as possible. An extendable notational framework should be simple, straightforward, and easy to understand. It should also be as similar as possible to the existing notations and be extendable for future developments [15].

A semi-structured approach was chosen, combining the gaps with the known consolidated elements. This literature review was not an exhaustive study as it would encompass too many areas of expertise. The review was rather focused on well-established and renowned authors for each one of these sections identified. The author selection criteria were based on established books, the number of citations and author experience. With the chosen literature curated, the chapters and sections of each one of these served as a main guide and skeleton for the elements needed to add to the framework.

Once the appropriate chapters and sections from the literature (including non-scientific outputs) were selected, the approach taken was to combine some of the elements that were consistent between them, or that added specific value to each portion, instead of including all of them in the framework. The combination of all the mentioned components within the literature review would entail a complete result. However, it would also make it too complex or extensive for real applicability. A fine tuning of the authors with previous management experiences was required to logically assemble some of the main principles, which were relatable and simple enough to be understood and used by the target audience.

With the content filtered and curated, text explanations were created alongside a visual representation to improve the association. The basic mental structures and processes benefited from the associated networks of verbal and image representations and the effects of context distributed this activation among the representations [16]. Geared towards increasing the usability of the tool, this paper used both images and text to facilitate the assimilation by the end-users.

The visual interpretation was supported by the software Figma (www.figma.com accessed on 16 January 2021). The icons used were sourced from an online and free repository, SVGRepo (www.svgrepo.com accessed on 16 January 2021), due to its extensive library of relevant representations of this framework.

\section{Results}

\subsection{Commonalities and Gaps Faced by the Current Practitioners}

A good overview of what needs to be considered when building an aquaponics system can be gathered from the themes which were questioned in previous surveys. 
The main topics addressed include: (i) Background, motivations, experiences, knowledge and education; (ii) Facility size, location, and design; (iii) Inputs such as water, energy, and fish feed; (iv) Outputs such as fish and crops; and (v) Revenue, profit, funding and investment [8-10,12].

From the pool of selected publications, we can also gather some insights. In [13], for instance, it was mentioned that the main topics addressed in the publications on aquaponics were: system structure and mechanics; water chemistry and microbiology; economics and management; plant and fish species selection; and fish and plant health. In addition, [5] also discussed the trends in the following categories: aquaponics systems; hydroponic components; fish species; plant species; and nitrifying bacteria, microflora, and additional species. In a more focused overview on crop yield in aquaponics, publications [17] mentioned: fish species, feed protein content, flow rates, aquaculture effluent $\mathrm{pH}$, fish density, feeding rate, and coupling type (coupled or decoupled systems). To be more precise with respect to the coupling type, [18] introduced the idea of permanent or on-demand coupled systems, instead of coupled or decoupled systems.

The investigation of the challenges of aquaponics as a commercial endeavor [4] shows that the elements that affect the economic viability of an aquaponics system may depend on factors such as: climate, energy consumption, location, wage levels, workload required, legal conditions, fish-plant combination, prices, organic possibility, and public acceptance. Additionally, [13] suggested that the establishment of large-scale aquaponics as an economically sustainable industry might benefit from: financial and risk management; consumer perception versus willingness to pay more; and ways to internalize the economic value of environmental benefits. On the same note, the main reasons for abandonment were: investment costs; unexpected regulation; lack of skilled labor; competition on market prices; season/climate; the cost of labor and energy sources; and water sources [19].

\subsection{Categorization for Focused Literature Review}

Analyzing the pool of practitioners and researchers in all areas of aquaponics, including those criticizing aquaponics, we were able to formulate a critical separation into three main categories in which a more in-depth analysis could be performed. Firstly, current frameworks on creating and maintaining a competitive business were researched. Secondly, literature on the peculiarities of running an aquaponics system was gathered to render the elements that were specific to this context. Lastly, research was conducted on an endeavor's viability analysis to ensure that businesses and people would be able to generate enough revenue to pay the costs and to provide returns over investments. With all these aspects, it can be assumed that the main elements needed to create the structure can be approached.

\subsubsection{Business Management}

For this section of the literature review, some of the main textbooks were reviewed, as well as the common frameworks used by companies, especially by business consultants. Some of the data were researched on online search engines as business-related frameworks were not necessarily scientifically published, but rather created as a community practice and used by enterprises. Three different examples were used from these sources: Business Model Canvas (BMC)—Osterwalder et al., 2010 [20]; Management Frameworks: Aligning Strategic Thinking and Execution-Kemp, Schotter and Witzel, 2012 [21]; SlideBooks ConsultingDomont, A., 2020 [22]. Aside from these, three more structured sources from renowned frameworks were also considered: Marketing Management_-(Kotler and Keller, 2012) [23]; Competitive advantage-Porter, M., 1985 [24]; Life cycle Cost-Fabrycky and Blanchard, 1991, referenced in Asiedu and Gu, 1998 [25].

\subsubsection{Aquaponics}

In this section of the literature review, three different established literature topics were studied: aquaponics, hydroponics, and aquaculture. An aquaponics book written by a collegiate of research was used: Aquaponics Food Production System—Goddek et al., 2019 [26]. 
A specific commercial aquaponics book was also used: Commercial Aquaponic SystemsLennard W., 2017 [27]. As a world guide for aquaponics, FAO put together the paper: 'Small-scale aquaponic food production: integrated fish and plant farming'-Somerville et al., 2015 [28]. For a hydroponics guide from Taylor and Francis we used: Hydroponic Food Production, 7th edition-Resh, 2012 [29]. Finally, focusing not only on aquaculture but also on financial viability, another FAO sponsored paper was used: 'Economic engineering applied to the fishery industry' - Zugarramurdi and Parin, 1995 [30].

\subsubsection{Viability Analysis}

The financial viability analysis has already become state-of-the-art and as such, a textbook that has stood the test of time, as it is currently in its 16th edition, was used as the main source: Financial Management_Brigham and Ehrardt, 2014 [31].

\subsection{Analyzing Frequent and Relevant Topics}

By combining all the data, it is possible to perceive some similarities and topics that can be seen across the literature. Of these elements, some can be nested amongst themselves while some are details within broader scopes. As mentioned before, the idea of the framework is to be complete enough and relevant and simple enough that it can be applied by all the target people. The next step was to aggregate, separate, and categorize some elements, as stated in this section.

The environmental portion provides the overall context in terms of all the elements that need to be considered, not only from a climate perspective but also considering desirability, feasibility and even expectations on returns over investment. This portion includes the motivations behind not only the practitioners but also the possible investors and the market in which it is inserted. This section was separated according to the existing PESTLE framework approach: Political, Economic, Social, Technological, Legal, Environmental.

Within a certain environment, the market is inserted with its current needs, comparison basis and expectations. The market dictates the prices that can be practiced for each one of the revenue streams such as fish, plants and adjacent services related to the current novelty of the system. The market conditions also dictate where and how these revenue streams are received. As such, a combination of all marketing-related sections within the selected literature was ensembled: Channel and Clients, Price and Promotion, Differentiation, and Risk \& Substitutes.

Enclosed by the market, the value chain dictates how the products or services will be sourced, produced, and delivered. 'Value chain' is a widely used term and it is common in all the business and marketing related literature. Porter (1998) created a related framework that encompassed all the value chain activities needed to manage and generate revenue, as well as plan for certain costs. These elements were originally separated as primary and support activities; however, for the purpose of simplification they are not categorized in this framework as they are all important activities that need to be planned and executed. The activities are separated as: Firm Infrastructure, Human Resources Management, Technology development, Procurement, Inbound Logistics, Operations, Outbound Logistics, Marketing and Sales, and Service.

Within the operations of the value chain, the actual physical and technical portion of the system happens. This has been the focus of most of the materials related to aquaponics, not only research but also courses, explanation videos, and webinars since they are the core of the whole system. The operations have a tangency with all the other activities within the value chain, from sourcing the controlled inputs to managing the harvesting. Because aquaponics has such specificities regarding this, these control inputs are explicitly related to the relevant organisms and are in the framework created. The control inputs can be separated into necessary and potentially additional inputs depending on business choice and situation:

- Fish will always have the necessary inputs of fish younglings and feed and, in some cases, might receive additional oxygen. 
- Greens are named this way because they can be plants or algae. As such, the necessary inputs are either seedlings, young plants, or algae spores. Depending on the system type, there can be inputs of the substrate, nutrients, pollinator or equivalent, and carbon dioxide.

- Aside from the fish and greens, there are system synergies within an aquaponics system. These necessary inputs are water, which is the connecting medium; energy; and controls such as $\mathrm{pH}$, temperature, nutrients or salts, suspended solids, oxygen, pest and disease control, and ultraviolet lights for sterilization, among others. Depending on the system requirements and choices, there might be: an additional carbon source (i.e.,: Biofloc systems); specific microbiota that can be inserted [32]; beneficial insects (i.e.,: Ladybugs); and even worms [33].

For all the systems to be run, there needs to be an investment in adequate infrastructure. There is infrastructure in all the main components: Administration and Logistics; Recirculating Aquaculture System (RAS); System Synergies (Sludge, Nutrients, etc.); the Hydroponic System; and Service Infrastructure. Depending on all the conditions of the environment, as well as the definitions regarding the go-to-market and value chain strategy, this infrastructure might be cheaper or more expensive. Therefore, these infrastructure costs will impact the investment level of the entire endeavor.

Combining the revenues from the sales of fish, greens and/or service and the value chain costs, a Cash Flow analysis can be created to determine how much money will be left in each of the time periods. The viability of the endeavor will depend on how the Cash Flow, for a specific time horizon, will cover the investments with its due cost of capital (WACC). There are numerous ways to evaluate the viability of an endeavor. However, the most cited and used method is the Net Present Value, which calculates the value that the businesses will generate considering all the cash flows and investments made in the time period and the payback period, which in turn calculates how much time the investment will take to be paid [31].

\subsection{Creating the Text Elements to Be Considered}

\subsubsection{Environment}

- Political: Political issues are the hardest to tackle and quantify. Organic or other certifications are very country-specific and might not be completely established and stable. Additionally, some countries might have a great political instability or even an inherent corruption. The motivation and relationship between all the stakeholders might also suffer from instability which offers a risk to the sustainability of the business.

- Economic: The economic environment will determine the stability of the venture as well as the willingness of the customer to pay certain prices. If there is a fluctuating exchange rate, or if there is economic instability where a supplier or a client might go bankrupt, some risk-mitigating measures must be taken (such as hedging operations) which will have a negative impact on costs and might even make the business not worth pursuing.

- Social: Social aspects are important considering not only the market preferences but also the workforce and community. In some countries, workers might work on weekends while in other countries, this might not be allowed or be cost-prohibitive. Additionally, some specific labor-intensive functions, such as manual pollination, might not be the best option in some places. Some countries require security to manage theft and property security. In these cases, this will most likely need to be a continuous job that will entail a substantial amount of costs. A risk assessment should be arranged including a realistic cost study.

- Technological: Depending on the type of the aquaponics system chosen, the level of technology can be determined. Certain technologies might not be available in a specific region and might need to be imported or developed, incurring costs such as time, working capital, and import taxes. Additionally, the maintenance and skilled 
workers required to operate such systems need to be included in the investment and/or on recurring costs.

- Legal: The legal context will permeate the stakeholders such as the founding partners, the bank, the suppliers, and the clients. A legal advisor might be needed for contracts, labor laws or government-related issues, as well as for handling customer complaints in a professional manner and representing the company if it is sued.

- Environmental: The temperatures, humidity, and solar radiation of the local weather, as well as day length, partly determines the business opportunities. The chosen species of plant, fish and microbiota have very specific needs in terms of temperature and energy requirements. Reaching these requirements might render the business costs prohibitive.

\subsubsection{Market}

- Channel and Clients: The client will provide the needed revenue for the enterprise. There are numerous possibilities of whom these products can be sold to. For aquaponics products, the distribution channels can be the sales to the wholesalers and retailers, or even online, in restaurants, or delivered directly to the client. It might even be that the most common source of income is derived from the services related to the knowledge of aquaponics with system design, courses, visits, and consulting [19].

- Price and Promotion: A study conducted in Europe suggested that only $17 \%$ of people were willing to pay more for aquaponic products [34]. Marketing strategies need to be considered for a premium price to be captured. These strategies can be very expensive and render poor results if not conducted correctly. Additionally, depending on the environment, some prices will not be reached even with extensive promotional efforts.

- Differentiation: Aquaponics products in the USA can be certified as organic if certain rules are followed [35]. However, in other countries, such as those in the European Union, this may not be a possibility [36]. Products can also be differentiated if there is a premium for locally produced products [34]. Different differentiation techniques might be employed; however, the costs for these techniques need to be accounted for.

- Risk \& Substitutes: Aquaponics products compete with any other agricultural system that produces the same products or even similar products that can be substituted. Fish, for example, can be substituted with chicken as a protein source depending on the price, availability, and customer's preference. Understanding the possible alternatives that the customer has will help comprehend the risks more accurately. Other risks related to the environmental aspects also need to be put into perspective.

\subsubsection{Value Chain}

- Firm Infrastructure: Infrastructure supports the entire value chain and not just the individual activities. General management, planning, finance, accounting, legal, government affairs, and quality management are crucial in any company, even in small, commercial aquaponics. All these activities can be concentrated on one person, distributed in many areas, or even attributed to consultants or third parties.

- Human Resources Management: Human resource management supports not only the direct hiring of people but also the possible broader scopes such as labor negotiations. The main related activities are recruiting, hiring, training, development, and compensation. Without qualified people managing, overseeing, and operating the business, it is not likely to succeed, especially in such a knowledge-intensive endeavor as aquaponics.

- Technology: The array of technologies employed in most firms is very broad, ranging from those technologies used in preparing documents and transporting goods to technologies embodied in the product itself. Technology development consists of a range of activities that can be broadly grouped into efforts to improve the product and the process, also known as research and development (R\&D). For such an innovative 
undertaking as aquaponics, $R \& D$ is a constant activity, especially in high-technology systems with extensive equipment and controls.

- Procurement: Procurement refers to the function of purchasing the needed inputs. There can be recurrent purchases such as feed and seeds but there are also important assets such as greenhouse and laboratory equipment. Improved purchasing practices can strongly affect the cost and quality of the purchased inputs. The activities associated with receiving and using the inputs and interacting with suppliers are also within the procurement's function.

- Internal Logistics: Items that are purchased also require activities associated with receiving, storing, and disseminating the inputs to the product, such as material handling, warehousing, inventory control, vehicle scheduling, and returns to suppliers. The conditions for storing seeds or young plants, for example, need to be well monitored with controlled environments.

- External Logistics: These are activities associated with collecting, storing, and physically distributing the products to buyers, such as finished goods warehousing, material handling, delivery vehicle operation, order processing, and scheduling. The external logistics of this can be very simple or very complex depending on the defined distribution channels through which each product is pursued.

- Sales \& Marketing: Especially for such a novel system as aquaponics, these activities can be the main focus as they dictate the revenue that will be collected. This entails providing a means by which buyers can purchase the product and inducing them to do so through advertising, promotion, salesforce, quoting, channel selection, channel relations, and pricing.

- Services: If a part of the revenue stream comes from selling knowledge, the service section might entail many of the activities. Even if there are no explicit service sales, there are still activities associated with providing service to enhance or maintain the value of the product, such as installation, repair, training, parts supply, and product adjustment.

\subsubsection{Operations}

Within the value chain are all the operations activities that are associated with transforming inputs into the final product form. A production calendar with adequate planning of when to buy the inputs and when to sell the outputs (if applicable) needs to be established to have a correct plan for resources, costs, and revenues. This calendar will provide the values needed for the Cash Flow that will be presented in the following section.

- Fish or relevant aquatic organisms: All the activities related to feeding, maintaining, controlling disease, and harvesting, packaging, and dealing with the fish residues need to be accounted for. The fish species and breeding or buying options need to be carefully chosen and accounted for because of specific needs (temperature, $\mathrm{pH}$, protein, spacing, etc.) and possible outcomes (weight and time at harvest and potential losses).

- Plants or relevant organisms: There are numerous possibilities of ways to grow greens in many different systems (NFT, media beds, aeroponics, coupled, decoupled, etc.). These systems have been extensively researched. The choice will influence the space and inputs needed, as well as the time and personnel commitments. The system type will also determine the frequency or need for the substrates and nutrients. If there is a need for or choice of using a controlled environment, such as a greenhouse, additional carbon dioxide can also be used, albeit at a cost. If the chosen species require pollination, such activities and related costs must also be accounted for.

- Synergies: An aquaponics system will have inherent microbiota for the transformations to occur permanently and on-demand coupled systems vary in the ways these synergies are integrated. The chosen technologies and automation levels will dictate not only yields but also requirements, investment needs and the recurring costs associated with them. Independent of which system design is used, all will require energy, water and at least some controls. These elements are exemplified in Table 1. 
Table 1. Requirements, availability, investment need and recurring costs associated with aquaponics synergies.

Element $\begin{gathered}\text { Requirements, Availability, Investment Need and Recurring Costs } \\ \text { One of the challenges presented to run an aquaponics unit versus traditional farming } \\ \text { methods is the dependency on energy. Energy is used throughout the whole system for } \\ \text { heating, artificial lighting, cooling, and moving water through the pumps, as well as for all the } \\ \text { facilities, computers, freezers, and vehicles, etc. It can be considered as electricity or gas from } \\ \text { a bioreactor or from renewable resources and/or the grid. A combination of the generation } \\ \text { and storage options must be analyzed according to the region, the cost of the electrical grid } \\ \text { usage, cost of maintenance, the initial investment, and the availability of each one. }\end{gathered}$
Wue to the plant's evapotranspiration and other spillages, water needs to be replenished
frequently. There needs to be an estimation of how much water will need to be treated
monthly to calculate the cost of the water. Availability, investment need, risk and cost are the
essential decision-makers for the choice of water supply.

\subsubsection{Investment}

Aquaponics will always require an aquaculture, usually a Recirculating Aquaculture System (RAS), and a hydroponic component. These will constitute the main part of all the investment required and will account for the operating costs [2]. However, there is also necessary support infrastructure that entails further investments and costs. Independent on the system sizing, there will be a need to set-up an administrative and logistics infrastructure, such as bathrooms, receiving areas, and computers. If the system is coupled on-demand, a considerable amount of infrastructure will be needed for the treatment of sludge and nutrients requiring reactors, nutrient concentrators, other equipment, and dedicated areas for this equipment. If a portion of the revenue is used for education, some service infrastructures might also require a considerable amount of space which, depending on the chosen location, might entail considerable costs.

For the system to become an enterprise, investments are required [37]. They can be separated into equipment, land, construction, improvements, and working capital. Sometimes a smaller investment will require higher recurring costs, while a larger investment might have smaller costs over the years (i.e., buying versus leasing). These two must be factored out in time to evaluate their viability. There are scarce data on the return of the investment in aquaponics; however, as a basis, two different cases reported a payback period of around 7 years [19].

\subsubsection{Viability—NPV \& Payback}

According to [31], to make an investment analysis, three basic facts need to be understood: (i) any asset is only valuable if it generates cash flows, (ii) the timing of the cash flows is important, and (iii) investors are averse to risk, so all else equal, they will pay more for certain rather than risky operations. Financing the business will most likely be needed because the investments occur before the revenues. This can be financed in many ways and the correct path depends on the business case's economic analysis. The investment needs to give the desired return to all the stakeholders involved. In a small company with only one owner, the only stakeholder is oneself. However, most companies have many stakeholders with different expectations of the value of their money.

\subsection{Creating a Visual Representation}

With these references in mind and connecting the elements from all of them, the following framework was created. The representation attempted to encompass not only the elements already mentioned but also the relationship between them, in order to reach the final goal which is the viability of the business with the due choices of fish and plant species, the system type, and the sales channel represented in Figure 1. 


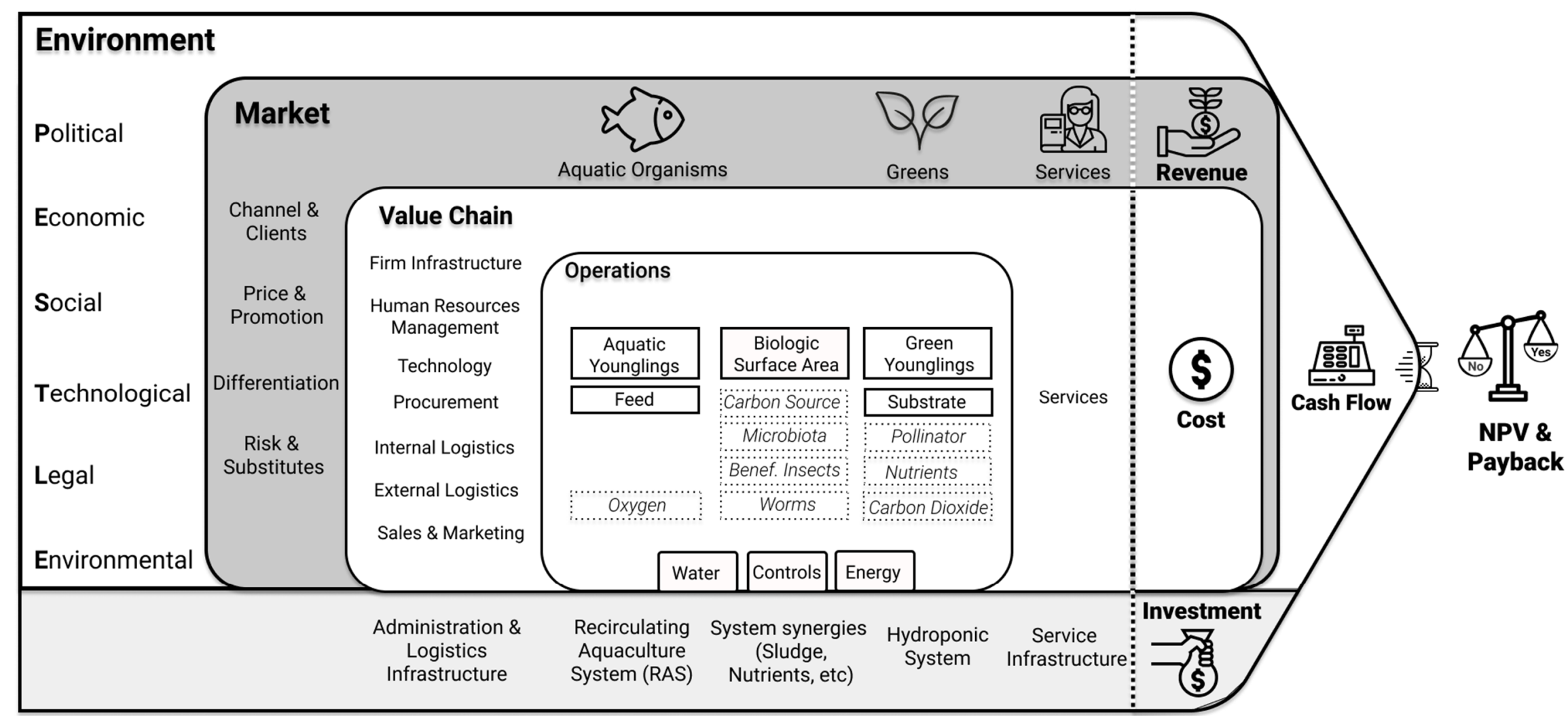

D Necessary Inputs

E." Optional Inputs

Figure 1. Framework created with all the elements considered and curated to make aquaponics a business. Making Aquaponics a Business Framework. 
The Environment determines all other factors that are nested within it. The investments are the basis for the business to be sustained and are separated by system type. The Market will generate the revenue and its elements are constrained by the level of investment carried out and the environment in which the business is placed. The strategy of how to deliver to the market is encompassed by the activities defined in the Value Chain which entail people and costs. The activity that is the most detailed is the Operations that are the most unique to aquaponics. Within the operations, the inputs are vertically aligned with the market Revenue and the Investment basis. For example, the fish revenue depends on the fish's operational costs, such as the cost of younglings, feed and possibly oxygen passing through the activities and costs (including water, controls, and energy). All of these will rely on the RAS investment. All the revenues minus the costs throughout time will create the Cash Flow. The cash flows in time, minus the investment, will render the Net Present Value (NPV). The moment in time when the revenues pay for the costs and investments is the payback period.

\section{Discussion}

According to [4], there is little literature on the economics of aquaponics as most of it focuses on the modelling. Without realistic data, projections are often overly optimistic because they have insufficient details on expenses. Conversely, they focus more on the fish and feed costs and overlook the inherent risks.

Our proposed framework provides a guideline to plan all the necessary elements needed to evaluate the feasibility of a commercial aquaponics enterprise within a certain context. This combination of findings provides some support for the conceptual premise that not all elements are considered and correctly researched when building an aquaponics endeavor. As such, many cases of aquaponics businesses do not prosper or cannot survive adversities. Therefore, these results need to be interpreted with caution as they only contain broad concepts and do not delve into the specifics that are needed. Because of the broadness of the concepts, these findings will doubtless be scrutinized, but there are some immediately dependable points of action that can be grasped from the framework, such as specific areas in which to study and plan for. To develop a full picture of all the elements, it is recommended that the literature review be thoroughly read, as well as additional studies that might close some knowledge gaps specific to the end-user.

This framework is intended for researchers, practitioners, and investors. Researchers might use this to categorize which area within the framework they are exploring. This can help to search more easily for specific areas and to identify research gaps within the current literature. It can also facilitate in grant applications and academic research projects as it can guide the necessary aspects to consider and the costs. Practitioners can use this to plan, adjust, or develop a robust business case for funding. During operations, it is also useful to adjust and understand their impact in economic feasibility. They can also employ a better use of knowledge search for questions to consultants. Large-scale aquaponics farms are usually not built because investors require practical proof of the concept which small-scale farms are not able to provide [19]. By using a framework such as this, investors have a reliable area of questions to ask founding partners regarding whether each element adds value to the overall system. If these elements have thorough planning for time, costs, and investments in a cash flow overview, then the investor might be more willing to grant funds.

There are still many unanswered questions about the interconnections between the elements. The possible attainable yield, depending on factors such as stocking density, system type or possible temperatures are not represented. Additionally, nutrient availability, versus plant requirements to determine crop size, is a specific answer that needs to be accounted for and is not explicitly present in the framework. It is not intended to dissect all the cause-and-effect relationships. For this, more detailed approaches and even specific biochemical flow models might render better results. 


\section{Future Research}

This study is only the tip of the iceberg of all the circumstances that might affect these endeavors. There are still some areas of exploration that warrant research. The expected costs of different systems and equipment within each type of system and their respective return on investment are still unclear. Additionally, a more in-depth investigation on aquaponics' financial viability analysis, including the cost of capital and investment options such as grants, needs exploration. The stakeholder expectations on the return on investment for an aquaponics business is also unknown and might add to the actual financial analysis. A more practical guide of questions that need to be answered before investing in aquaponics might aid practitioners and investors moving forward. Ideally, this framework might also serve as a basis to compare real-world case studies which are adequate for investors to evaluate benefits without dreading unknown risks.

\section{Conclusions}

The intent of this framework is to elucidate all the possible elements that can be of risk to the viability of a business. Testing different scenarios of fish or plant species, system types, market prices and strategies will help users to make fewer mistakes along the way by creating a successful aquaponics venture. This guide allows for experimenting with trial and error, which is best conducted during a planning phase where the costs are much lower than when the system is operating. This practical guide, intended to help leverage profitable commercial aquaponics businesses throughout the world, was based on the accumulated knowledge of the cited researchers within the different fields. The literature base from which this was created was more specific to each individual element and is also encouraged to be studied according to each individual's knowledge gap.

Author Contributions: Conceptualization, L.S.A.; methodology, L.S.A.; software, L.S.A.; validation, K.J.K. and S.G.; formal analysis, K.J.K. and S.G.; investigation, L.S.A.; resources, L.S.A.; data curation, K.J.K. and S.G.; writing-original draft preparation, L.S.A.; writing-review and editing, K.J.K. and S.G.; visualization, L.S.A.; supervision, K.J.K. and S.G.; project administration, K.J.K.; funding acquisition, K.J.K. All authors have read and agreed to the published version of the manuscript.

Funding: This research received no external funding.

Institutional Review Board Statement: Not applicable.

Informed Consent Statement: Not applicable.

Data Availability Statement: MDPI Research Data Policies.

Acknowledgments: This work is part of the BlueCycling project that has received funding from the European Union's Horizon 2020 research and innovation program under grant agreement No 862555 within the 2019 Joint Call of the ERA-NET Cofund on Food Systems and Climate.

Conflicts of Interest: The authors declare no conflict of interest.

\section{References}

1. Naegel, L.C.A. Combined production of fish and plants in recirculating water. Aquaculture 1977, 10, 17-24. [CrossRef]

2. Goddek, S.; Delaide, B.; Mankasingh, U.; Ragnarsdottir, K.; Jijakli, H.; Thorarinsdottir, R. Challenges of Sustainable and Commercial Aquaponics. Sustainability 2015, 7, 4199-4224. [CrossRef]

3. Suhl, J.; Dannehl, D.; Zechmeister, L.; Baganz, D.; Kloas, W.; Lehmann, B.; Scheibe, G.; Schmidt, U. Prospects and challenges of double recirculating aquaponic systems (DRAPS) for intensive plant production. Acta Hortic. 2018, 1227, 449-456. [CrossRef]

4. Turnšek, M.; Morgenstern, R.; Schröter, I.; Mergenthaler, M.; Hüttel, S.; Leyer, M. Commercial Aquaponics: A Long Road Ahead. In Aquaponics Food Production Systems; Goddek, S., Joyce, A., Kotzen, B., Burnell, G.M., Eds.; Springer International Publishing: Cham, Switzerland, 2019; pp. 453-485. [CrossRef]

5. Yep, B.; Zheng, Y. Aquaponic trends and challenges-A review. J. Clean. Prod. 2019, 228, 1586-1599. [CrossRef]

6. Hao, Y.; Ding, K.; Xu, Y.; Tang, Y.; Liu, D.; Li, G. States, Trends, and Future of Aquaponics Research. Sustainability $2020,12,7783$. [CrossRef]

7. Proksch, G.; Baganz, D. CITYFOOD: Research Design for an International, Transdisciplinary Collaboration. Technol. I Archit. + Des. 2020, 4, 35-43. [CrossRef] 
8. $\quad$ Love, D.C.; Fry, J.P.; Genello, L.; Hill, E.S.; Frederick, J.A.; Li, X.; Semmens, K. An International Survey of Aquaponics Practitioners. PLoS ONE 2014, 9, e102662. [CrossRef] [PubMed]

9. Villarroel, M.; Junge, R.; Komives, T.; König, B.; Plaza, I.; Bittsánszky, A.; Joly, A. Survey of Aquaponics in Europe. Water 2016, 8, 468. [CrossRef]

10. Mchunu, N.; Lagerwall, G.; Senzanje, A. Aquaponics in South Africa: Results of a national survey. Aquac. Rep. 2018, 12, 12-19. [CrossRef]

11. Greenfeld, A.; Becker, N.; Bornman, J.F.; Angel, D.L. Identifying knowledge levels of aquaponics adopters. Environ. Sci. Pollut. Res. 2020, 27, 4536-4540. [CrossRef] [PubMed]

12. Love, D.C.; Fry, J.P.; Li, X.; Hill, E.S.; Genello, L.; Semmens, K.; Thompson, R.E. Commercial aquaponics production and profitability: Findings from an international survey. Aquaculture 2015, 435, 67-74. [CrossRef]

13. Greenfeld, A.; Becker, N.; McIlwain, J.; Fotedar, R.; Bornman, J.F. Bornman, Economically viable aquaponics? Identifying the gap between potential and current uncertainties. Rev. Aquac. 2019, 11, 848-862. [CrossRef]

14. Cambridge, Framework I BUSINESS ENGLISH. Definition of Framework from the Cambridge Business English Dictionary@ Cambridge University Press. 2020. Available online: https://dictionary.cambridge.org/dictionary/english/framework (accessed on 17 October 2020).

15. Corominas, L.L.; Rieger, L.; Takács, I.; Ekama, G.; Hauduc, H.; Vanrolleghem, P.A.; Oehmen, A.; Gernaey, K.V.; van Loosdrecht, M.C.; Comeau, Y. New framework for standardized notation in wastewater treatment modelling. Water Sci. Technol. 2010, 61, 841-857. [CrossRef] [PubMed]

16. Clark, J.M.; Paivio, A. Dual coding theory and education. Educ. Psychol. Rev. 1991, 3, 149-210. [CrossRef]

17. Ayipio, E.; Wells, D.E.; McQuilling, A.; Wilson, A.E. Comparisons between Aquaponic and Conventional Hydroponic Crop Yields: A Meta-Analysis. Sustainability 2019, 11, 6511. [CrossRef]

18. Baganz, G.; Baganz, D.; Staaks, G.; Monsees, H.; Kloas, W. Profitability of multi-loop aquaponics: Year-long production data, economic scenarios and a comprehensive model case. Aquac. Res. 2020, 51, 2711-2724. [CrossRef]

19. Turnšek, M.; Joly, A.; Thorarinsdottir, R.; Junge, R. Challenges of Commercial Aquaponics in Europe: Beyond the Hype. Water 2020, 12, 306. [CrossRef]

20. Osterwalder, A.; Pigneur, Y.; Clark, T. Business Model Generation: A Handbook for Visionaries, Game Changers, and Challengers; Wiley: Hoboken, NJ, USA, 2010.

21. Kemp, J.; Schotter, A.; Witzel, M. Management Frameworks: Aligning Strategic Thinking and Execution; Routledge: Oxfordshire, UK, 2012.

22. Domont, A. SlideBooks Consulting. Available online: https://www.slidebooks.com/ (accessed on 1 May 2020).

23. Kotler, P.; Keller, K.L. A Framework for Marketing Management, 5th ed.; Prentice Hall: Boston, MA, USA, 2012.

24. Porter, M. Competitive Advantage: Creating and Sustaining Superior Performance-With a New Introduction; Free Press: New York, NY, USA, 1998.

25. Asiedu, Y.; Gu, P. Product life cycle cost analysis: State of the art review. Int. J. Prod. Res. 1998, 36, 883-908. [CrossRef]

26. Goddek, S.; Joyce, A.; Kotzen, B.; Burnell, G.M. Aquaponics Food Production Systems: Combined Aquaculture and Hydroponic Production Technologies for the Future; Springer International Publishing: Berlin/Heidelberg, Germany, 2019. [CrossRef]

27. Lennard, W. Commercial Aquaponic Systems: Integrating Recirculating Fish Culture with Hydroponic Plant Production; Aquaponic Solutions: Victoria, Australia, 2017.

28. Somerville, C.; Cohen, M.; Pantanella, E.; Stankus, A.; Lovatelli, A. Small-Scale Aquaponic Food Production: Integrated Fish and Plant Farming; Food and Agriculture Organization of the United Nations: Rome, Italy, 2015.

29. Resh, H.M. Hydroponic Food Production, 7th ed.; CRC Press: Boca Raton, FL, USA, 2012. [CrossRef]

30. Zugarramurdi, A. Economic Engineering Applied to the Fishery Industry (FAO). 1995. Available online: http://www.fao.org/3/ v8490e/V8490E00.HTM\#Contents (accessed on 3 February 2021).

31. Brigham, E.F.; Ehrhardt, M.C. Financial Management: Theory and Practice, 14th ed.; South-Western Cengage Learning: Mason, OH, USA, 2014.

32. Martin-Ryals, A.D. Evaluating the Potential for Improving Anaerobic Digestion of Cellulosic Waste via Routine Bioaugmentation and Alkaline Pretreatment. Master's Thesis, University of Illinois, Champaign, IL, USA, 2012.

33. Kotzen, B.; Emerenciano, M.G.C.; Moheimani, N.; Burnell, G.M. Aquaponics: Alternative Types and Approaches. In Aquaponics Food Production Systems; Goddek, S., Joyce, A., Kotzen, B., Burnell, G.M., Eds.; Springer International Publishing: Cham, Switzerland, 2019; pp. 301-330. [CrossRef]

34. Miličić, V.; Thorarinsdottir, R.; Santos, M.; Hančič, M. Commercial Aquaponics Approaching the European Market: To Consumers' Perceptions of Aquaponics Products in Europe. Water 2017, 9, 80. [CrossRef]

35. USDA Agricultural Marketing Service. Status of Organic Hydroponics, Aquaponics, Aeroponics; National Organic Standards Board Fall 2017 Updates, 25 January 2018. Available online: https:/ / content.govdelivery.com/accounts/USDAAMS/bulletins/ 1cde3b0 (accessed on 21 June 2021).

36. Kledal, P.R.; König, B.; Matulić, D. Aquaponics: The Ugly Duckling in Organic Regulation. In Aquaponics Food Production Systems; Goddek, S., Joyce, A., Kotzen, B., Burnell, G.M., Eds.; Springer International Publishing: Cham, Switzerland, 2019 ; pp. 487-500. [CrossRef]

37. Engle, C.R. Economics of Aquaponics. 2015. Available online: https://lens.org/061-709-957-706-263 (accessed on 5 June 2021). 